\title{
Câncer gástrico na Coréia do Sul - visão de um cirurgião brasileiro
}

\section{UICC ICRETT fellowship em cancer gástrico}

ReINALDo ISAACs BERON ${ }^{1}$

Sr. Editor,

$\mathrm{D}$ acordo com dados publicados pelo Instituto Nacional de Câncer Brasileiro as estimativas de 2010 referentes a câncer de estômago indicam 21500 novos casos, dos quais, dois terços (13820) será em homens e 7680 em mulheres. A mortalidade desta neoplasia varia da segunda á quarta mais letal no Brasil, sendo os estados do sudeste e nordeste os locais de maior incidência.

Na Coréia do Sul, com uma população de pouco mais de um quarto da população brasileira, o problema é muito mais grave. Publicações recentes de aproximados 26253 novos casos em 2010 e colocam o câncer gástrico como o mais prevalente e a segunda causa de morte relacionada a câncer nesse pais. Ao contrario de paises ocidentais, dentre eles o Brasil, onde a maioria das lesões são de localização proximal na Coreia, assim como na China e no Japão (as três juntas concentram mais da metade dos casos mundiais de câncer gástrico), a prevalência das lesões é no estômago distal.

As publicações asiáticas são referencias mundiais no estudo e tratamento do câncer gástrico. Ultimamente a Coréia do Sul vem se destacando na cirurgia principalmente na Laparoscopia e Cirurgia Robótica.

Com essa visão aplicamos para uma Bolsa de Estudos da UICC (ICRETT) para visitarmos o serviço de Cirurgia de Câncer Gástrico da Universidade Nacional de Seul. Este serviço coordenado pelo Prof. Yang tem reconhecimento mundial e volume de cirurgias gástricas somente comparados com alguns centros do Japão. O professor Yang será o Secretario Geral do próximo Congresso Mundial de Cancer Gástrico em 2011 em Seul.

Por trinta dias tive oportunidade de acompanhar o Serviço da SNUH por quatro semanas, como parte fundamental do Fellowship de Transferência de Tecnologia em Pesquisa de Câncer (ICRETT) da União Internacional de Combate ao Câncer (UICC). Esse estagio incluía acompanhar o dia-a-dia da equipe liderada pelo professor $\mathrm{Dr}$. Han Kwang Yang, que computam mais de 20 mil casos de câncer gástrico operados.

Durante o estagio no SNUH acompanhei 36 cirurgias de câncer gástrico sendo 30 realizadas pelo Prof. Yang. Deste subgrupo 18 eram do sexo masculino e 12 do feminino. Dezesseis casos eram câncer gástrico avançado
(AGC) e 14 precoce (EGC), Essa distribuição está de acordo com estudos recentes que demonstram o aumento de incidencia de EGC na Coreia do Sul para aproximadamente $50 \%$ dos casos. O serviço de endoscopia da SNUH é responsável pelo diagnóstico de câncer precoce. O emprego sistemático da eco-endoscopia e clipagem tumoral préoperatoria $1 \mathrm{~cm}$ proximal e distal a lesão tem permitido aos cirurgiões coreanos oferecer tratamento minimamente invasivo.

Das cirurgias realizadas a gastrectomia subtotal com reconstrução a $\mathrm{BI}$ (RSG-BI) aparece como a mais comum (oito casos), depois aparecem a gastrectomia total (TG) cinco casos e a gastrectomia distal laparoscopicamente assistida ( $L A D G$ ) em cinco casos. Quatro casos de gastrectomia subtotal a BII (RSG-BII) e para a gastrectomia com preservação do piloro laparoscopicamente assisitida (LAPPG), como parte da investigação de novas tecnicas com preservação da funçao do orgão. Uma gastrectomia total laparoscopicamente assistida (LATG) tinha como proposta inicial de LAPPG mas devido a uma margem proximal comprometida optou-se pela conversão a TG. Duas ressecções paliativas por carcinomatose peritoneal sendo uma gastrectomia paliativa e uma derivação gastro-enterica.

A dissecção linfonodal foi sempre a D2 e mais de 50 linfonodos ressecados nas cirurgias curativas dependendo obviamente da localização do epicentro do tumor de acordo com os guidelines da International and Japanese Gastric Cancer Association. Essa dissecção das estações linfonodais é realizada pela equipe cirúrgica após a retirada da peça. A dissecção linfonodal peritumoral é reservada ao patologista para melhor avaliar a invasão tumoral da serosa e dos tecidos adjacentes.

A citologia e estudo de linfonodo sentinela não são procedimentos de rotina no SNUH, e são atualmente motivos de estudo no SNUH Cancer Research Institute. Outros estudos estão em andamento como o KLASS trial; estudo multicêntrico, randomizado que compara a cirurgia laparoscópica com a aberta tanto para EGC quanto para AGC. O estudo REGGATTA que compara o efeito da gastrectomia paliativa no sobrevida global versus o tratamento clínico sem cirurgia.

Durante o estagio ocorreram três eventos internacionais: $17^{\circ}$ Simposio Internacional de Cancer Gastrico e Novas Tecnicas e Terapias no Genoma do Cancer ambos

1. Especializando em Gastroenterologia Cirurgica. Universidade Federal de São Paulo - Escola Paulista de Medicina. 
realizados no SNUH e o Simposio Internacional de Cancer Gastrico "East versus West" realizado no Saint Mary's Hospital de Seoul da Universidade Católica da Coreia, com o Professor Takeshi Sano do Cancer Institute Hospital do Japão e a Dra Vivian Strong do Memorial Sloan Kettering Cancer Center de New York, uma das precursoras de abordagens minimamente invasivas para cancer de estômago nos EUA. A promoção e troca de informações fazem parte da pesquisa e troca de experiências entre outros centros que também tratam do Cancer Gástrico e uma atividade comum na Coreia.

Ainda há muito a ser definido na prevenção, deteccão e manejo adequado de doentes com cancer de estomago na Coréia do Sul. Apesar de inumeros estudos ocidentais com menores taxas de sobrevida em cinco anos após cirurgia de intenção curativa, quando comparados com estudos orientais, o impacto de uma linfadenectomia extendida não esta claramente resolvido. Existem diferencias não somente histologicas e de localização do tumor, mas tambem de exposição ambiental, fatores dieteticos, infecção por $\mathrm{H}$. Pylori e inclusive biometricas que devem ser levadas em consideração para propor o melhor tratamento aos nossos doentes.

A experiência obtida no SNUH é de um valor muito importante para minha carreira, no so no ambito cirurgico mas tambem como um ponto de referencia de outra cultura, de outra realidade onde este tipo de tumor e muito mais prevalente e as medidas para combate-lo sao mais drasticas e agressivas. Recomendo a cirurgioes, oncologistas, endoscopistas ou outros profisionais da saude interessados em Câncer Gástrico a visitar este centro de excelência.

Gostaria de agradeçer ao Prof. Dr Laercio Gomes Lourenço, ao Prof. Dr Han Kwang Yang e a UICC pela apoio para a realização desta atividade. 